Document downloaded from:

http://hdl.handle.net/10251/50020

This paper must be cited as:

Berzisa, S.; Bravos, G.; Cardona Gonzalez, T.; Czubayko, U.; España, S.; Grabis, J.; Henkel, M.... (2015). Capability driven development: an approach to designing digital enterprises. Business and Information Systems Engineering. 57(1):15-25. doi:10.1007/s12599-014-0362-0.

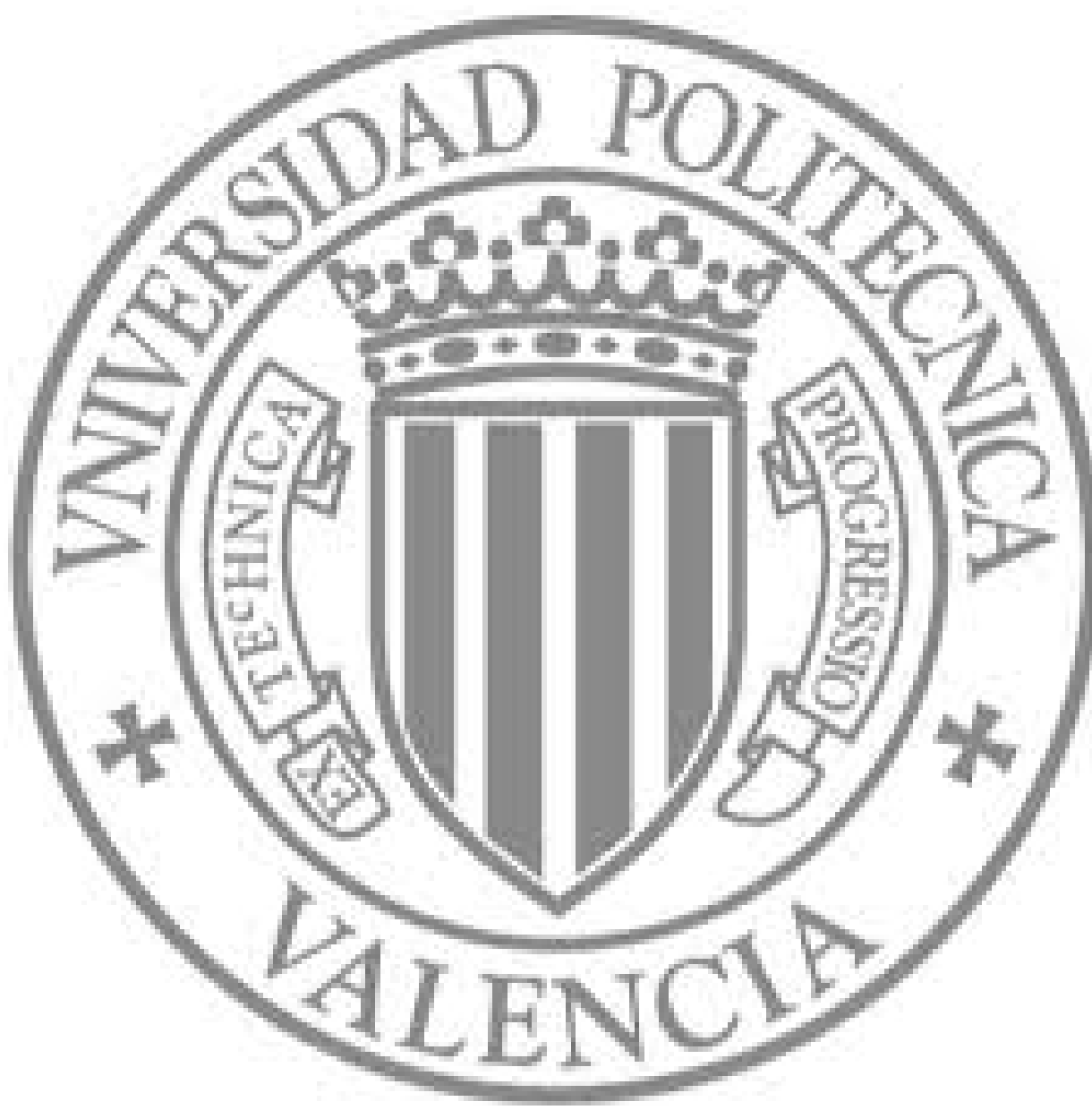

The final publication is available at

http://link.springer.com/article/10.1007/s12599-014-0362-0

Copyright

Springer Verlag (Germany) 
This is a pre-print draft of the following paper, whose copyright is owned by Springer:

Bērziša, S., G. Bravos, T. Gonzalez, U. Czubayko, S. España, J. Grabis, M. Henkel, L. Jokste, J. Kampars, H. Koç, J.C. Kuhr, C. Llorca, P. Loucopoulos, R. Juanes, O. Pastor, K. Sandkuhl, H. Simic, J. Stirna, F. Valverde and J. Zdravkovic (2015). "Capability Driven Development: an approach to designing digital enterprises." Business \& Information Systems Engineering: 1-11.

\title{
Capability Driven Development: An Approach to Designing Digital Enterprises
}

\begin{abstract}
The need for organizations to operate in changing environments is addressed by proposing an approach that integrates organizational development with information system (IS) development taking into account changes in the application context of the solution. This is referred to as Capability Driven Development (CDD). A meta-model representing business and IS designs consisting of goals, key performance indicators, capabilities, context and capability delivery patterns, is being proposed. The use of the meta-model is validated in three industrial case studies as part of an ongoing collaboration project, whereas one case is presented in the paper. Issues related to the use of the CDD approach, namely, CDD methodology and tool support are also discussed.
\end{abstract}

Keywords. Enterprise modeling, capabilities, capability driven development, model driven development

\section{Introduction}

To improve alignment between business and information technology, information system (IS) developers continuously strive to increase the level of abstraction of development artifacts. A key focus area is making the IS designs more accessible to business stakeholders to articulate their business needs more efficiently. These developments include object-orientation, component based development, business process modeling, enterprise modeling (EM) and software services design. These techniques are mainly aimed at capturing relatively stable, core properties of business problems and on representing functional aspects of the IS (Wesenberg, 2011). However, the prevalence and volatility of the Internet shifts the problem solving focus to capturing instantaneous business opportunities (Deloitte, 2009). Furthermore, the context of use for modern IS is not always predictable at the time of design; instead an IS should have the capability to support different contexts which implies that, we should consider the context of use and under which circumstances the IS, in congruence with the business system, can provide the needed business capability. Hence, an IS capability is determined not only during the design-time but also at runtime when its ability to handle changes in different contexts is put to test. As an example, airport operations use different patterns to cope with different levels of passenger flow at times of different events, e.g. when many passengers are stranded at once which leads to surges in demand for various services. Tackling the issues of IS supporting different contexts is especially relevant for modern digital enterprises. Digital enterprises are enterprises possessing digital resources and providing an important share of its services digitally by customizing the essential services to meet requirements of customers facing specific operating circumstances. Such enterprises continuously monitor changes in the business context in order to identify opportunities for capitalizing on these changes.

A capability-driven approach to development should be able to alleviate all such issues and to produce solutions that fit the actual application context.

From the business perspective, we define a capability as the ability and capacity that enable an enterprise to achieve a business goal in a certain context. Ability refers to the level of available competence, where competence is understood as talent intelligence and disposition, of a subject or enterprise to accomplish a goal; capacity means availability of resources, e.g. money, time, personnel, tools.Note here that capacity, being the amount of available resources, is an integral part of a capability. IS applications (and their execution environments) can be an important part of capabilities. This means that it is important to tailor these applications with regard to functionality, usability, reliability and other factors required by users operating in varying contexts. This puts pressure on IS development and delivery methods. The IS development industry has responded by elaborating Model Driven Development (MDD) methods and by adopting standardized design and delivery approaches such as service-oriented architecture and cloud computing. However, there are a number of major challenges when it comes to making use of MDD to address business capabilities:

The gap between business requirements and current MDD techniques. MDD approaches and tools still operate with artifacts defined on a relatively low abstraction level. 
- Inability to model execution contexts. In complex and dynamically changing business environments, modeling just a service providing business functionality in a limited context of execution is not sufficient.

- High cost for developing IS that work in different business contexts. Developers, especially SMEs, have difficulties to market their software globally because of the effort it takes to adhere to localization requirements and constraints in the business context of where the software will be used.

- Limited support for modeling changes in non-functional requirements. Model-driven approaches focus on functional aspects at a given time point, rather than representing evolution of both functional and non-functional IS requirements over time.

- Limited support for "plasticity" in applications. The current context-aware and front-end adaptation systems focus mainly on technical aspects (e.g., location awareness and using different devices) rather than on business context awareness.

- $\quad$ Limited platform usage. Limited modeling support for defining the ability of the IS to make use of new platforms, such as cloud computing platforms because it is a technology driven phenomenon, and there is little guidance for development of cloud based business applications.

We propose to support the development of capabilities by using EM techniques as a starting point of the development process and to use model-based patterns to describe how the software application can adhere to changes in the execution context. Our vision is to apply enterprise models representing enterprise capabilities to create executable software with built-in contextualization patterns thus leading to Capability Driven Development ( $C D D)$.

The objective of this paper is to present the CDD meta-model, to discuss its feasibility by using an example case, and to outline a number of open development issues related to practical adoption of the CDD approach.

The research approach taken in this paper is conceptual and argumentative. Concepts used in EM, context representation and service specification are combined together to establish the CDD meta-model. Validation of the meta-model is performed using the cases of companies in the fields of e-governance, compliance, and business process outsourcing. Application of the meta-model is outlined by analyzing its role in development of capability delivery applications. The CDD methodology is proposed following the principles of agile and iterative IS development methodologies. The work presented in this paper is a continuation of our work presented in (Stirna et al., 2012) and (Zdravkovic et al., 2013). Compared to these publications, in this paper we present a refined CDD meta-model, a new case study where the CDD approach has been applied, and a validation of the approach.

The remainder of the paper is organized as follows. Section 2 sets the scene for the CDD approach in terms of related work and the requirements for CDD. In section 3 requirements for CDD are discussed. Section 4 presents the CDD meta-model. It is applied to a validation case in section 5. Section 6 discusses aspects of development methodology need for the CDD approach. The paper concludes in section 7 with a number of reflective remarks.

\section{Background}

\section{Related Work}

In the strategic management discipline, a company's resources and capabilities are, for a long time, seen as the primary source of profitability and competitive advantage. Barney has united them into what has become known as the resource-based view of the company (Barney, 1991). Accordingly, Michael Porter's value chain identifies top-level activities with the capabilities needed to accomplish them (Porter, 1985). In Strategy Maps and Balanced Scorecards, Kaplan and Norton also analyze capabilities through the company's perspectives, e.g. financial, customers', and other (Kaplan \& Norton, 2004).

In research within Business-IT alignment, there have been attempts to consider resources and capabilities as the core components in enterprise models, more specifically, in business value models (Osterwalder \& Pigneur, 2003; Kinderen, Gordijn \& Akkermans, 2009). However, in none of these works, capabilities are linked to IS models in a structured and systematic way. In the SOA reference architecture (OASIS, 2011) a capability is described as a business functionality that, through a service, delivers a well-defined user need. However, in the specification, little attention is given to the modeling of capabilities. In Web Service research, capability is considered purely 
on the technical level, through service level agreements and policy specifications (Papazoglou \& Yang, 2003).

In order to reduce development time, to improve software quality, and to increase development flexibility, MDD has established itself as a promising IS development approach. However, Asadi and Ramsin (2008) show that the Model Driven Architecture (Kleppe, Warmer \& Bast, 2003), a de-facto standard for MDD, and its associated methodologies mainly assume requirements as given a priori. Loniewski, Insfran \& Abrahao (2010) and Yue, Briand \& Labiche (2011) indicate that MDA starts with system analysis' models. They also survey various methods for integrating requirements into an overall model-driven framework, but do not address the issue of requirements origination. There is a limited evidence of MDA providing the promised benefits (Mohagheghi \& Dehlen, 2008). Complexity of tools, their methodological weaknesses, and too low abstraction level of development artifacts are among the main areas of improvement for MDD tools (Henkel \& Stirna, 2010).

EM has been used for business development and early requirements elicitation for many years (Nilsson, Tollis \& Nellborn, 1999). However, a smooth, nearly automated, transition to IS development has not been achieved due to immaturity of the existing approaches and lack of tools. Enterprise-wide models are also found in various Enterprise Architecture development approaches, for example, where the enterprise architecture of ArchiMate (2008) is extended with an intentional aspect capturing the goals and requirements for creating an enterprise system. A comparable solution is developed in (Pastor \& Giachetti, 2010), where a generic process is presented for linking $i^{*}$ and the OO-Method as two representatives of Goal-Oriented Requirements Engineering (GORE) and MDD, respectively. Furthermore, a systematic transition from goals to business process models (Ruiz et al., 2014), and from business process models to UML-based specifications (González et al., 2011) is being developed, but its industrial application and adoption is yet to be demonstrated.

Methods for capturing context in applications and services have achieved high level of maturity and they provide a basis for application of context information in IS development and execution. Vale and Hammoudi (2009) describe MDD for context-aware applications, where the context model is bound to a business model, encompassing information about user's location, time, profile, etc. Context awareness has been extensively explored for Web Services, both methods and architectures, as reported in (Sheng, Yu \& Dustar, 2010). It is also studied in relation to workflow adaptation (Smanchat, Ling \& Indrawan, 2008). Lately, Hervas, Bravo and Fontecha (2010) have suggested a formal context model, compounded by ontologies describing users, devices, environment and services.

In summary, there are a number or contributions to addressing the problem of adjusting IS depending on the context, however the concept of business capability is not explicitly addressed.

\section{Requirements for Capability Driven Development}

Currently the business situation in which an IS will be used is predetermined at design time. At run-time, only adaptations that are within the scope of the planned situation can usually be made. But in many cases we need rapid response to changes in the business context and development of new capabilities, which also requires run-time configuration and adjustment of the IS. In this respect a meta-model for capability modeling, linking business designs with application contexts and IS components is needed.

Designing capabilities is a task that combines both business and IS knowledge. A review of existing practice (Jarke et al., 2011) shows that implementation and its requirements specification are now closely intertwined. Hence both domains need to be integrated in such a way that allows establishing IS support for the business capabilities.

Current EM and business development approaches have grown from the principle that a single business model is owned by a single company. In spite of distributed value chains and virtual organizations this way of designing organizations and their IS still prevails. The CDD approach aims to support co-development and co-existence of several business models by providing "connection points" between business models based on goals and business capabilities.

Most of the current implementations of MDD approaches do not support development of more advanced features e.g. complex calculations, advanced user interfaces, scalability of the application in the cloud. CDD should contribute to the state of art by supporting the modeling of the application execution context; this includes modeling the ability to switch service providers and platforms. 


\section{Foundations for Capability Driven Development}

The CDD meta-model presented in this section provides the methodological foundation for the CDD. In this paper, the term CDD meta-model is used to denote the high-level language defined for expressing the models as used when applying the CDD. The meta-model thus contains the central concepts that are used, and their relationships; therefore it specifies the abstract syntax and the semantics for modeling during CDD. The meta-model is developed on the basis of industrial requirements and related research on capabilities. The CDD meta-model is shown in Figure 1. The meta-model has three main parts:

- Enterprise and capability modeling for developing organizational designs that can be configured according to the context dependent capabilities in which they will be used. This part of the meta-model captures a set of generic solutions applicable in many different business situations.

- Capability delivery context modeling of situations under which the solutions should be applied including indicators for measuring the context properties.

- Capability delivery patterns representing reusable solutions for reaching business goals under different contexts. The context defined for the capability should match the context in which the pattern is applicable in.

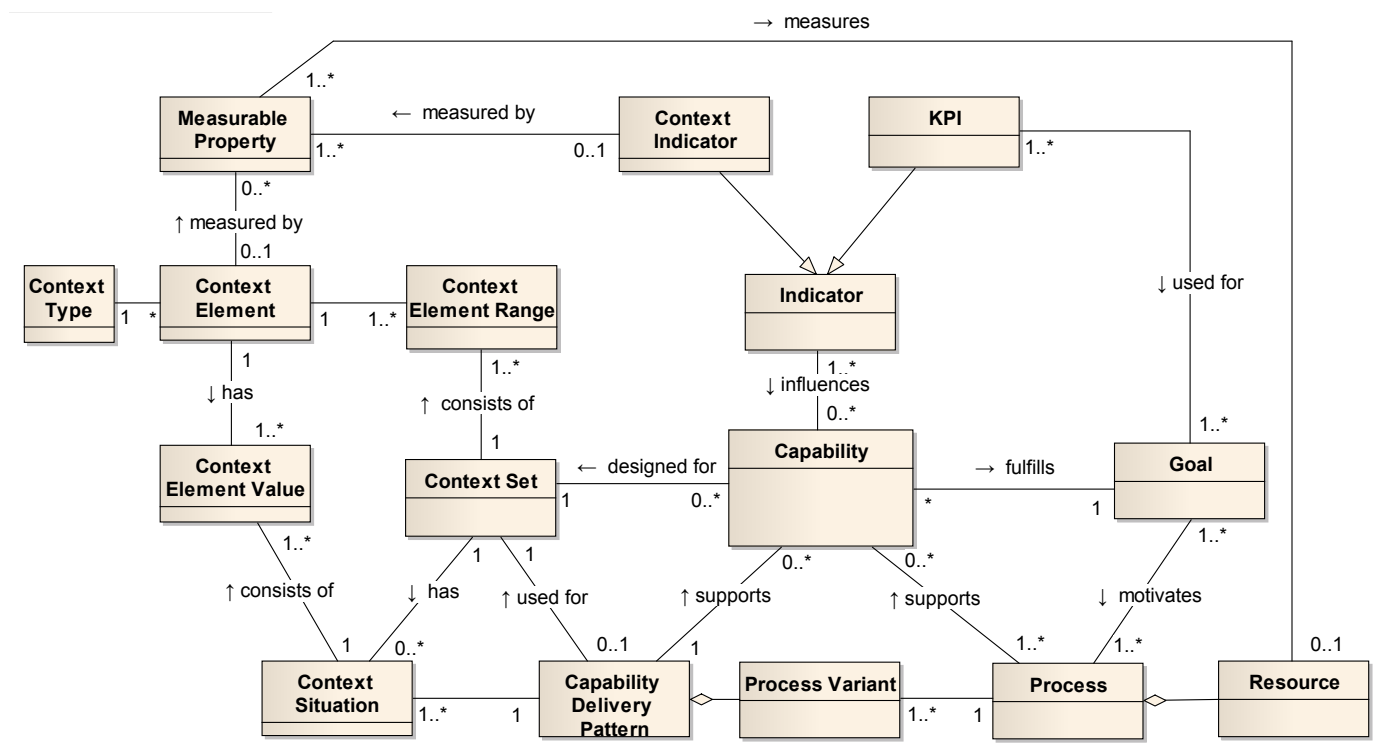

Fig. 1. The CDD meta-model

\section{Enterprise and Capability Modeling}

This part covers modeling of business goals, key performance indicators $(K P I)$, and business processes needed to accomplish the goals. KPIs are performance measurements used for monitoring goal fulfilment. We also specify resources required to perform processes. The associations between these modeling components are based on the meta-model of the EM approach EKD (Bubenko, Persson \& Stirna, 2001). The concept of capability extends EKD towards being suitable for CDD.

Capability is the ability and capacity that enable an enterprise to achieve a business goal in a certain context. Capability is the core element that describes the part of the business that will be designed and delivered by the CDD approach. Capability formulates the requirements for the ability of accomplishing a business goal, realized by applying a solution described by a capability delivery pattern.

Each capability requires or is motivated by one business goal. In principle business goals can be seen as internal means for designing and managing the organization and capabilities as offerings to external customers. A capability requires or is supported by specific business processes, each process utilizing a set of resources. The distinguishing characteristic of a capability is that it designed to be provided in a specific context. The desired goal fulfillment levels can be defined by using a set of indicators in the form of KPIs. 


\section{Context Modeling}

The context modeling part consists of context elements to describe the context constituents, as well as indicators in the form of measurable properties that can be used to monitor a specific context situation. The context is any information that can be used to characterize the situation (Dey, 2001), in which the capability can be provided. In the CDD meta-model the context set denotes a set of circumstances, such as geographical location, platforms and devices used, as well as business conditions and environment. These circumstances are described by the use of context elements, categorized by different context types. Each context element, such as geographical location, has a range of valid values as identified by its context element range. The purpose of context element range is to represent the actual ranges of value of relevant context elements for a specific context set. The context situation represents the current context status.

Each capability delivery pattern requires a specific context set as to be possible to apply. The context indicators represent context measurements, which are of vital importance for the capability delivery.

The context indicators are used to monitor whether the pattern chosen for capability delivery is still valid for the current context situation. If the pattern is not valid, then capability delivery should be dynamically adjusted by applying a different pattern or reconfiguring the existing pattern (i.e., changing delivery process, reassigning resources etc.). Technically, the context information is captured using a context platform in a standardized format, e.g. XCoA (Gomes et al., 2010).

\section{Capability Delivery Pattern}

In the CDD approach we amalgamate the principle of reuse and execution of patterns as good designs (c.f., for instance, Gamma, Helm, Johnson \& Vlissides, 1995) with the principle of sharing best practices in the form of organizational patterns. Hence, capability delivery patterns are reusable solutions for reaching business goals under specific context situation. The context defined for the capability (by the context set) should match the context in which the pattern is applicable. Patterns will represent reusable solutions in terms of business process variants, including resources, roles and supporting IT components (e.g. code fragments, web service definitions) for delivering a specific type of capability in a given context.

Each pattern describes how a certain capability is to be delivered within a certain context and what processes and resources are needed. In order to provide a fit between required resources and available resources, KPIs for monitoring capability delivery quality are defined in accordance with organization's goals. KPIs measure whether currently available resources are sufficient in the current context.

\section{Validation of the CDD Meta-model}

The goal of the meta-model validation is to test the suitability of the CDD meta-model in a realistic case. Correctness and expressiveness of the meta-model were the fundamental aspects to evaluate. The meta-model has been validated by modeling three companies in different fields: 1) egovernance, 2) compliance, and 3) business process outsourcing. More specifically, we developed capability models for the following industrial use cases:

1. At Everis (Spain) for service promotion capability, marriage registration capability, SOA platform capability.

2. Fresh T Limited (UK) for compliance capability.

3. SIV AG (Germany) for standard business processes execution capability.

The capability models were developed using the Enterprise Architect tool (Sparx Systems, 2013). The model elements are represented using UML 2.0 (OMG, 2011a), while process models are elaborated using BPMN 2.0 (OMG, 2011b). Due to space limitations this section only presents one case; the complete set of models is available in (Bērziša et al., 2014).

\section{Application case at Everis - Service Promotion Capability}

The purpose of the Service Promotion (SP) is to encourage the use of a service on municipality's e-government web portal. In particular, this is done in situations where a service is highly used in a municipality with a similar profile (number of citizens, location near the sea or inland, etc.). Each municipality using e-services has a service catalogue on its home page and 
several services can be promoted by highlighting them on the main page. Each municipality can follow different approaches on how to implement the highlighting. Some home pages have an ability to run automatic service highlighting (showing service in the main page), while some municipalities' home pages do not. The capability model of the SP case is shown in Figure 2, using the UML object diagram notation.

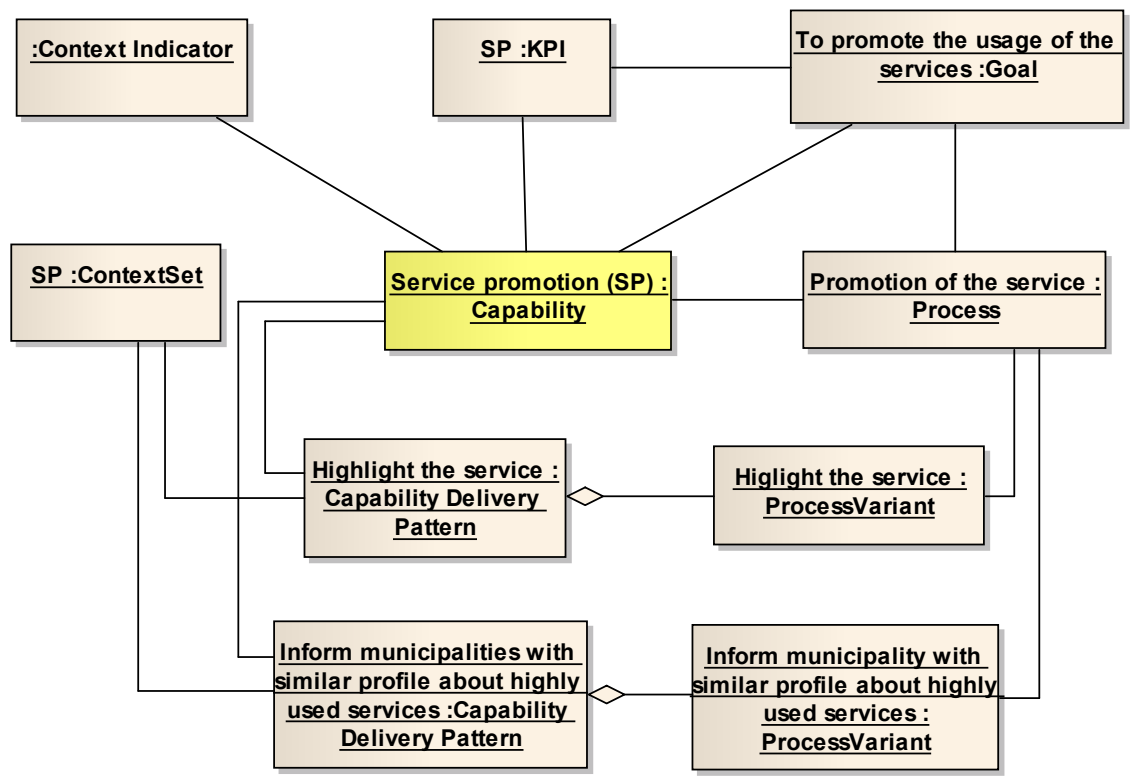

Fig. 2. Service Promotion (SP) Capability model

The main goal of the SP capability is to promote the usage of the online services. It is supported by several sub-goals, see Figure 3.

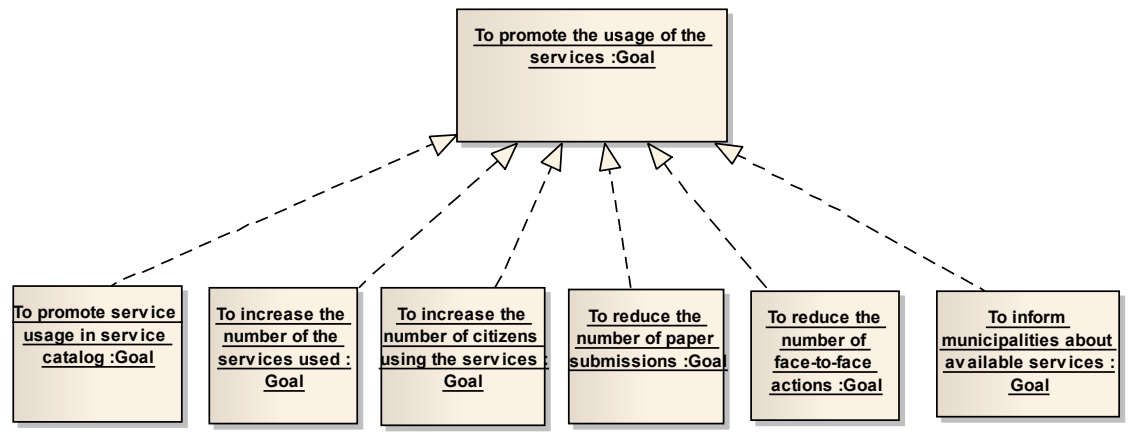

Fig. 3 SP Goals model

Each of the goals has one or more KPIs associated with it. A list of KPIs is given in Table 1:

Table 1. SP Goals KPI

\begin{tabular}{|l|l|l|l|}
\hline KPI name & Target value & Segments & Related Goal \\
\hline $\begin{array}{l}\text { \% of citizens consuming the } \\
\text { services }\end{array}$ & $25 \%$ & $\begin{array}{l}\text { Idle } \geq 25 \% \\
\text { Acceptable 5-25\% } \\
\text { Warning }<5 \%\end{array}$ & $\begin{array}{l}\text { To promote the usage } \\
\text { of the services }\end{array}$ \\
\hline $\begin{array}{l}\text { \% of services in active use } \\
\text { from all services provided } \\
\text { by municipality }\end{array}$ & $100 \%$ & $\begin{array}{l}\text { Idle }>90 \% \\
\text { Acceptable } 70-90 \% \\
\text { Improvable } 50-69 \% \\
\text { Warning }<50 \%\end{array}$ & $\begin{array}{l}\text { To increase the number } \\
\text { of the services used }\end{array}$ \\
\hline $\begin{array}{l}\text { Growth of the number of } \\
\text { citizens using the services } \\
\text { per month }\end{array}$ & $5 \%$ & $\begin{array}{l}\text { Idle } \geq 5 \% \\
\text { Acceptable } 1-4 \% \\
\text { Improvable } 0-1 \% \\
\text { Warning }<0 \%\end{array}$ & $\begin{array}{l}\text { To increase the number } \\
\text { of citizens using the } \\
\text { services }\end{array}$ \\
\hline $\begin{array}{l}\text { \% of completed service } \\
\text { actions/ submissions }\end{array}$ & $90 \%$ & $\begin{array}{l}\text { Idle: } \geq 90 \% \\
\text { Acceptable: } 50-90 \% \\
\text { Improvable }<50 \%\end{array}$ & $\begin{array}{l}\text { To increase the number } \\
\text { of completed service } \\
\text { actions/ submissions }\end{array}$ \\
\hline
\end{tabular}




\begin{tabular}{|l|l|l|l|}
\hline $\begin{array}{l}\text { \% of municipalities starting } \\
\text { to use a service after } \\
\text { received information }\end{array}$ & $90 \%$ & $\begin{array}{l}\text { Idle: } \geq 90 \% \\
\text { Acceptable: } 60-90 \% \\
\text { Improvable }<60 \%\end{array}$ & $\begin{array}{l}\text { To inform } \\
\text { municipalities about } \\
\text { available services }\end{array}$ \\
\hline $\begin{array}{l}\% \text { of face-to-face actions } \\
\text { (from all actions where } \\
\text { online service is available) }\end{array}$ & $30 \%$ & $\begin{array}{l}\text { Idle: } 0-30 \% \\
\text { Acceptable: } 31-40 \% \\
\text { Improvable }>40 \%\end{array}$ & $\begin{array}{l}\text { To reduce the number } \\
\text { of face-to-face actions }\end{array}$ \\
\hline $\begin{array}{l}\text { \% of paper submissions } \\
\text { (from all submissions where } \\
\text { online submission is } \\
\text { available) }\end{array}$ & $30 \%$ & $\begin{array}{l}\text { Idle: } 0-30 \% \\
\text { Acceptable: } 31-40 \%\end{array}$ & $\begin{array}{l}\text { To reduce the number } \\
\text { of paper submissions }\end{array}$ \\
\hline
\end{tabular}

The context representation is elaborated using a composite context model here summarized in table 2. It includes the list of context elements and their defined types. The measurable property concept defines the measurements for the specific context elements. The context element value and the context situation concepts are not shown here because they are instantiated only during the capability delivery phase. The context element has zero or more measurable properties because in the design time ways to measure some of the context elements might be unknown.

Table 2. SP Context elements in tabular view

\begin{tabular}{|c|c|c|c|c|}
\hline Context Element & $\begin{array}{l}\text { Context } \\
\text { type }\end{array}$ & Possible values & $\begin{array}{l}\text { Measurable } \\
\text { properties }\end{array}$ & $\begin{array}{l}\text { Mapping Measurable } \\
\text { Property to value }\end{array}$ \\
\hline Municipality size & Static & $\begin{array}{l}\text { \{Small, Medium, } \\
\text { Large }\}\end{array}$ & $\begin{array}{l}\text { Number of } \\
\text { citizens }\end{array}$ & $\begin{array}{l}\text { If number of citizens } \\
<10000 \text { then 'small' } \\
\text { If number of citizens } 10000 \text { - } \\
30000 \text { then 'medium' } \\
\text { If number of citizens }>30000 \\
\text { then 'large' }\end{array}$ \\
\hline $\begin{array}{l}\text { Usage of the } \\
\text { service in other } \\
\text { municipalities }\end{array}$ & Dynamic & $\begin{array}{l}\text { \{High, Medium, } \\
\text { Low }\}\end{array}$ & $\begin{array}{l}\text { Percentage of } \\
\text { municipalities } \\
\text { using the } \\
\text { service }\end{array}$ & $\begin{array}{l}\text { If municipalities using the } \\
\text { service }<20 \% \text {, then 'low' } \\
\text { If municipalities using the } \\
\text { service } 20-50 \% \text { then } \\
\text { 'medium' } \\
\text { If municipalities using the } \\
\text { service }>50 \% \text { then 'high' }\end{array}$ \\
\hline $\begin{array}{l}\text { Amount of } \\
\text { actions/submission } \\
\text { s per month }\end{array}$ & Dynamic & {$[0 \ldots 10000]$} & $\begin{array}{l}\text { Number of } \\
\text { actions/submi } \\
\text { ssions per } \\
\text { month }\end{array}$ & $\mathrm{n} / \mathrm{a}$ \\
\hline $\begin{array}{l}\text { Feedback in social } \\
\text { networks }\end{array}$ & Dynamic & $\begin{array}{l}\text { \{very negative, } \\
\text { negative, neutral, } \\
\text { positive, very } \\
\text { positive\} }\end{array}$ & $\begin{array}{l}\text { Number of } \\
\text { positive } \\
\text { remarks in } \\
\text { Facebook, } \\
\text { Twitter }\end{array}$ & $\begin{array}{l}\text { List of expressions/ key } \\
\text { words describing online } \\
\text { services feedback }\end{array}$ \\
\hline $\begin{array}{l}\text { Type of } \\
\text { highlighting }\end{array}$ & Static & $\begin{array}{l}\text { \{automatic, } \\
\text { manual }\end{array}$ & $\begin{array}{l}\text { Type of } \\
\text { highlighting }\end{array}$ & $\mathrm{n} / \mathrm{a}$ \\
\hline
\end{tabular}

The SP process has two main process variants in respect to how the services with a high usage in one municipality can be promoted in similar municipalities: if the municipality's home page has automatic service highlighting ability, then service highlighted procedure is executed. Depending on different context data, service highlighted procedure can be run once every 24 hours, or once every 72 hours. If automatic highlighting is not possible, or another municipality with similar profile does not have particular service, then an email is sent to the municipality, or to the project management office (PMO) about service promotion. Such factors or business drivers influencing the execution of the relevant process variant are summarized in Table 2, where context elements and their measurable properties are specified. Service usage (context) is monitored during the run time according to the following principles: 
- If service usage is high, then service can be highlighted in similar municipalities (similar size and profile);

- If citizens' feedback about service usage in social networks is positive, then service can be highlighted in similar municipalities (similar size and profile);

- If a municipality's portal does not have an ability to automatically highlight the service, an email to the municipality is sent about the high usage of particular services.

- If a municipality with similar profile does not have a particular service which has a high usage in other municipality, then the information about this service is sent to PMO about service dissemination.

The process model with process variants and capability delivery patterns is shown in Figure 4. In the capability model, process variants are presented as a separate concept from the main process, but in the process model they are included as the alternative paths to the main scenario. After the starting event of the process, an evaluation is done by an expression taking the context elements as inputs. In this case, the context elements used are the municipality size, usage of the service in other municipalities and feedback in social networks. The conditional expression uses these context elements to determine the need for running the service promotion process.

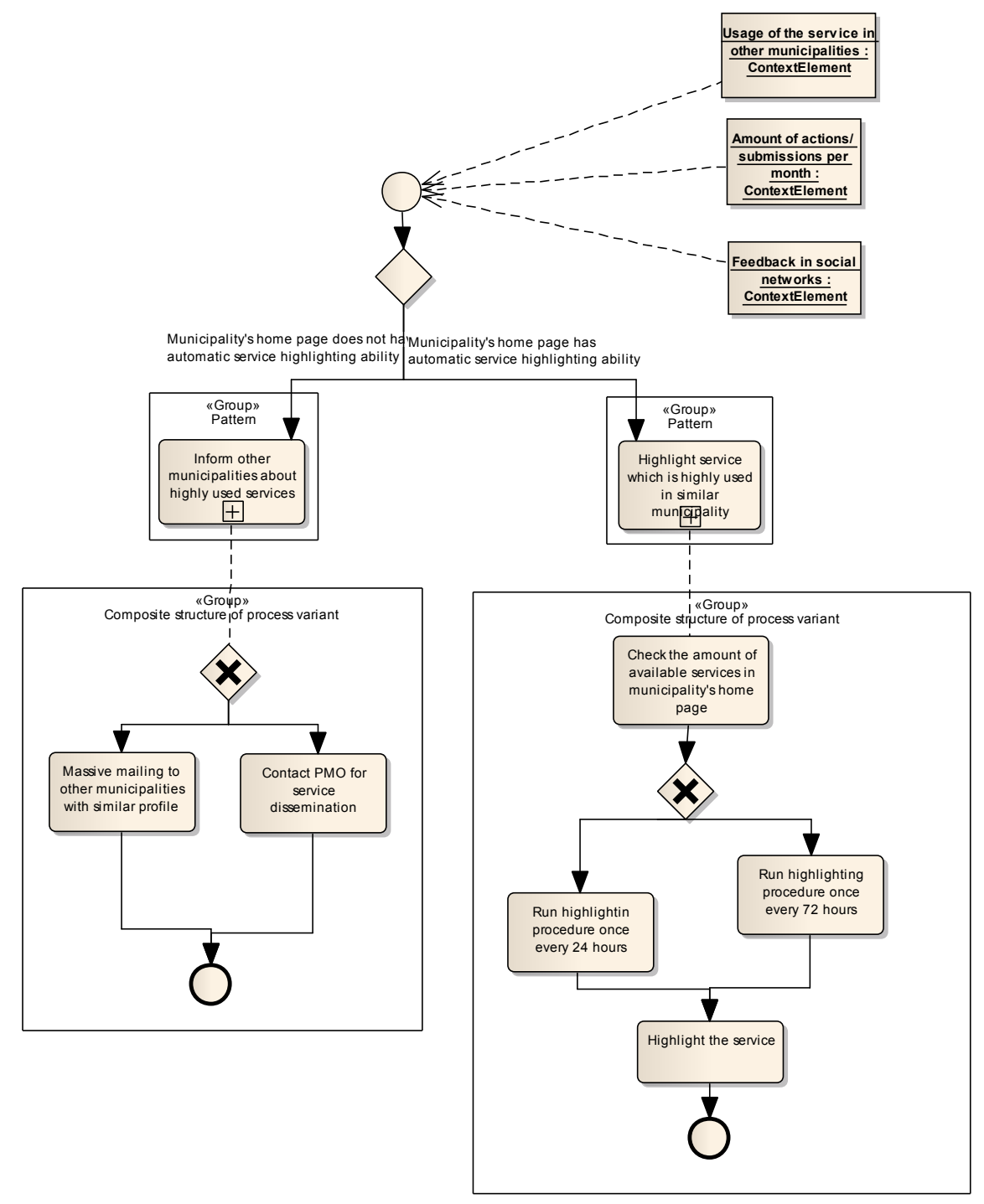

Fig. 4 SP Process model

For the presented case the following modeling observations can be made: 
1) The SP capability depends on the usage data for a large number of services, meaning that the usage of the service in other municipalities need to be monitored.

2) Process and process variants are dependent on the context data, thus the association between process and context situation (which describes the context data in capability delivery phase) is highly important for the SP capability.

3) Resources should be included in the capability model only if it has a significant role for delivering the capability. In this case, services are located in the SOA platform and highlighting is done automatically by a database procedure which is not treated as a resource.

\section{Validation results}

The capability models were developed for the three use cases and the companies have approved the models as sufficiently describing their business problems. However, several differences have been observed that should be taken into account during the further elaboration of the CDD methodology.

A majority of CDD meta-model concepts and their associations have been used in the instantiation of the meta-model. A detailed overview of usage of the concepts and associations is provided in (Bērziša el al., 2014). The resource concept was not used in some of the capability models. The context element and measurable property were related one-to-one, especially, for the context elements known at the design time. The context type was not always used in the model because its efficient use depends on the availability of a taxonomy of context types.

The process variant was used: 1) to represent variants of the capability process; and 2) to represent variation within the process variant itself. The former can be considered as global process variants while the latter can be seen as local process variants. The global process variants were represented using the process variant concept. The local process variants can be perceived as non-standard ways of business process modeling. Therefore, it is not directly represented in the CDD meta-model. It is assumed that local process variants are useful if there are many different process variants. Rules for developing process variants should be defined at the design time of the capability.

The pattern concept was used to represent: 1) the solution supporting the capability; and 2) reusable components used in design of the process variants. Similarly to the process variants the former can be seen as a global pattern supporting the capability as a whole and the latter can be seen as a local pattern supporting parts of the process. The global pattern is created for every new capability developed and latter can be used in design of new capabilities. The local patterns are retrieved from the pattern repository and are used to create process variants. The patterns also contain information about how to perform the run-time adjustment.

The validation results show that different approaches to specialization of capabilities are possible. The standard process delivery capabilities at SIV AG are further specialized depending on design time context situation while Everis SP capability is defined as an individual capability and context dependence occurs only within the capability definition. The CDD methodology should provide guidance for developing and managing hierarchy of related capabilities. The capability oriented specialization shows context dependence at the business level and process variants show context dependence at the business and conceptual solution level.

\section{Capability Driven Development Approach}

The CDD methodology is based on agile and model driven IS development principles and consists of the CDD development process, a language for representing capabilities according to the CDD meta-model, as well as modeling tools. The main principles of the CDD methodology are:

- Use of enterprise models understandable to business stakeholders,

- Support for a heterogeneous development environment as opposed to a single vendor platform,

- Equal importance of both design-time and run-time activities with clear focus on different development artifacts,

- Rapid development of applications specific to a business challenge,

- Search for the most economically and technically advantageous solution, 
An overview of the envisioned CDD process is shown in Figure 5. It includes three phases (Enterprise Modeling, Design, and Delivery) as well as two supporting activities (Management and Feedback).

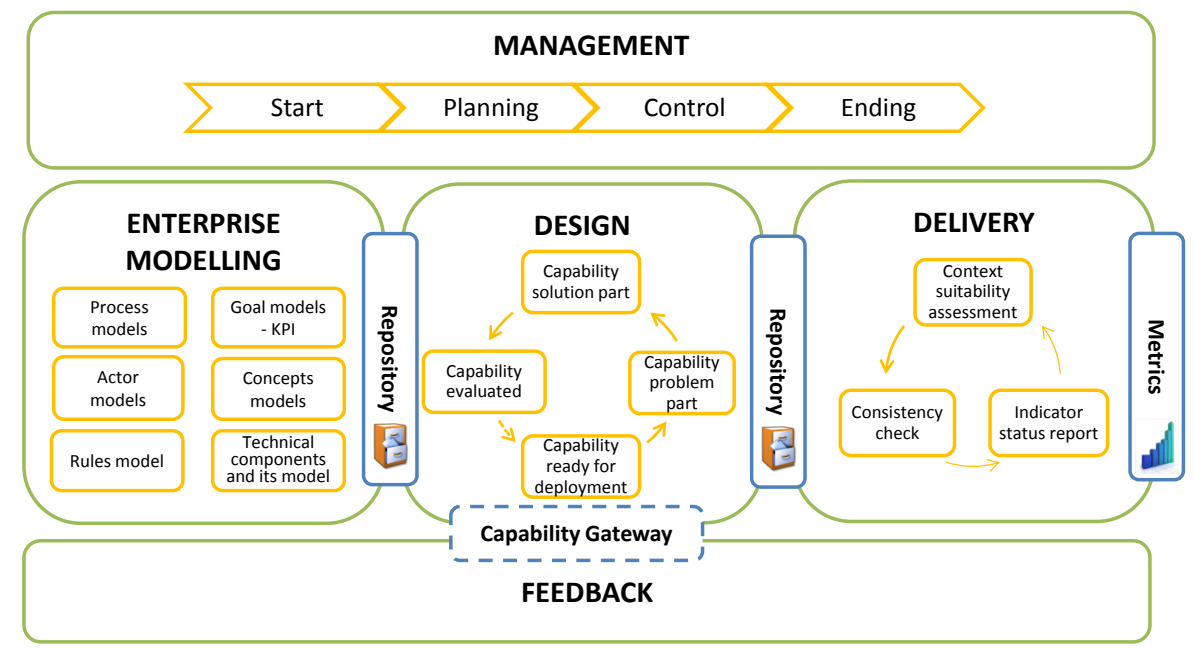

Fig. 5. CDD methodology

Enterprise Modeling helps defining the overall business design and its result serves as input for the capability design. Capabilities usually serve business objectives and are linked to business strategies. The interrelations between objectives, strategies, structures and processes are captured in enterprise models. Thus, capabilities often are designed on the basis of enterprise models. If the company already has some models in place, this phase can mostly focus on reviewing and, if needed, refining them. In other cases, if the capability to be designed addresses new business area and/or solutions, then the whole business design might need to be modeled first.

Design - the capability design explicitly focuses on evaluation of different business service designs in various delivery contexts as capabilities are being customized to specific requirements.

Delivery - the delivery phase concerns the actual utilization of the capability enabled by supporting information systems (i.e., capability delivery environment) with the intention to meet company's business goals in continuously evolving circumstances

Feedback activity is used mainly due to the need to take into account additional context factors because not all relevant factors can be identified during the first development iteration.

A management activity is explicitly represented in the CDD method to support its use in a project setting by supporting the capability development and management life-cycle including project planning, performing, control and ending activities.

\section{Concluding Remarks and Future Work}

We have proposed an approach, Capability Driven Development (CDD), that integrates organizational development with IS development taking into account changes in the application context of the solution. The approach is based on an EM process - it is based on EM components understandable to business stakeholders, such as goals, KPIs, processes, and resources and in principle is independent of any specific EM language. The linkage of the available enterprise components with different business contexts is done relying on the principle of reusing organizational patterns and the use of and execution of software patterns. In the CDD meta-model, patterns represent reusable solutions in terms of business process, resources, and supporting IT components for delivering a specific type of capability in a given context. We have presented a validation case from the e-government field.

Two important challenges to be addressed are the availability of patterns and the implementation of algorithms for dynamic adjustment of the CDA. In order to ensure pattern availability an infrastructure and methods for life-cycle management of patterns is required. In some cases, incentives for sharing patterns among companies can be devised. There could also be a selection of different adjustment algorithms. Elaboration and implementation should follow a set of general, open principles for incorporating algorithms developed by third parties. 


\section{Acknowledgements}

This work has been partially supported by the EU-FP7 funded project no: $611351 \mathrm{CaaS}$ Capability as a Service in Digital Enterprises.

\section{References}

ArchiMate, An enterprise modeling language from the Open Group. http://www.opengroup.org/archimate/

Asadi, M. and Ramsin, R (2008), MDA-Based Methodologies: An Analytical Survey, In proc of Model Driven Architecture-Foundations and Applications (ECMDA-FA 2008), LNCS 5095, pp 419-431.

Barney J.B, (1991) Firm Resources and Sustained Competitive Advantage. Journal of Management, 17(1), pp 99-120.

Bērziša, S., Bravos, G., Gonzalez Cardona T., Czubayko, U., España, S., Grabis, J., Henkel, M., Jokste, L., Kampars, J., Koc, H., Kuhr, J., Llorca, C., Loucopoulos, P., Juanes Pascual, R., Sandkuhl, K., Simic, H., Stirna, J., Zdravkovic. J. (2014), Deliverable 1.4: Requirements specification for CDD, CaaS - Capability as a Service for Digital Enterprises, FP7 project no 611351, Riga Technical University, Latvia. Submitted for review.

Bubenko, J. A. Jr., Persson, A. and Stirna, J. (2001). User Guide of the Knowledge Management Approach Using Enterprise Knowledge Patterns. Deliverable D3, IST Programme project Hypermedia and Pattern Based Knowledge Management for Smart Organisations, project no. IST-2000-28401, Royal Institute of Technology, Sweden.

Comuzzi, M., Pernici, B. (2009), A framework for QoS-based Web service contracting, ACM Transactions on the Web 3 (3)

Deloitte (2009), Cloud Computing: Forecasting Change, Deloitte Consulting, http://www.deloitte.com/assets/Dcom-

Netherlands/Local\%20Assets/Documents/EN/Services/Consulting/n1_en_consulting_cloud_comp uting_security_privacy_and_trust.pdf

Dey, A., (2001) Understanding and Using Context, Journal of Personal and Ubiquitous Computing, Springer 5(1), pp 4-7.

Gamma, E., Helm, R., Johnson, R. and Vlissides, J. (1995) Design Patterns: Elements of Reusable Object-Oriented Software Architecture. Addison Wesley

Gomes, D., Gonçalves, J.M., Santos R., and Aguiar, R. (2010) XMPP based Context Management Architecture, In: proc. of the GLOBECOM Workshop, IEEE, pp.1372-1377 (2010)

González, A., S. España, M. Ruiz and Ó. Pastor (2011). Systematic derivation of class diagrams from communication-oriented business process models. In 12th Working Conference on Business Process Modeling, Development, and Support (BPMDS'11), Springer LNBIP. 81, pp 246-260.

Henkel, M., Stirna J., (2010) Pondering on the Key Functionality of Model Driven Development Tools: the Case of Mendix, P. Forbrig and H. Günther (eds.), in proc. of Business Informatics Research (BIR 2010), Springer LNBIP 64, ISBN 978-3-642-16100-1

Hervas, R., Bravo, J. and Fontecha, J. (2010) A Context Model based on Ontological Languages; a proposal for Information Visualisation. Journal of Universal Computer Science (J.UCS) Vol. 16/12, pp 1539-1555.

Jarke, M., P. Loucopoulos, K. Lyytinen, J. Mylopoulos and W. Robinson (2011) The Brave New World of Design Requirements, Information Systems 36(7): pp 992-1008.

Kaplan, R.S., and Norton, D.P.: Strategy Maps: Converting Intangible Assets into Tangible Outcomes. Harvard Business School Press, Boston, MA (2004)

Kinderen, de, S., Gordijn, J., Akkermans, H. (2009) Reasoning about customer needs in multisupplier ICT service bundles using decision models. In Proceedings of the 11th International Conference on Enterprise Information Systems (ICEIS 2009), pp 131-136.

Kleppe, A., Warmer, J. and Bast, W. (2013), MDA Explained, Addison-Wesley Professional.

Loniewski, G., Insfran, E. and Abrahao, L. (2010), A Systematic Review of the Use of Requirements Engineering Techniques in Model-Driven Development, In proc. of Model driven engineering languages and systems (MODELS 2010), Part II, LNCS 6395, pp213-227.

Mohagheghi, P. and Dehlen, V. (2008) Where Is the Proof? - A Review of Experiences from Applying MDE in Industry, In proc of Model Driven Architecture-Foundations and Applications (ECMDA-FA 2008),, LNCS 5095, pp 432-443.

Nilsson, A. G., Tolis, C. and Nellborn, C. (Eds.) (1999), Perspectives on Business Modelling: Understanding and Changing Organisations, Springer-Verlag 
OASIS, (2011) Reference Architecture Foundation for Service Oriented Architecture Version 1.0, Committee Specification Draft 03 / Public Review Draft 0206 July 2011, http://docs.oasisopen.org/soa-rm/soa-ra/v1.0/soa-ra.pdf

OMG (2011a), UML Superstructure, http://www.omg.org/spec/UML/2.4.1/

OMG (2011b), Business Process Model and Notation http://www.omg.org/spec/BPMN/2.0/

Osterwlader, A., Pigneur, Y. (2003) Modeling value propositions in e-Business. Proceedings of the 5th International Conference on Electronic Commerce (ICEC 2003). ACM Conference Proceedings Series 50, ISBN 1-58113-788-5

Papazoglou, M. P. and Yang, J. (2003) Design Methodology for Web Services and Business Processes, In proc. of the Third International Workshop on Technologies for E-Services (TES 03), LNCS, Vol. 2444, Springer, pp 54-64.

Pastor, O., \& Giachetti, G. (2010). Linking Goal-Oriented Requirements and Model-Driven Development. In Intentional Perspectives on Information Systems Engineering Springer, pp 257276.

Porter, M.E.: Competitive Advantage: Creating and Sustaining Superior Performance, Free Press, New York (1985)

Ruiz, M., D. Costal, S. España, X. Franch and Ó. Pastor (2014). Integrating the goal and business process perspectives in information system analysis. In 26th International Conference on Advanced Information Systems Engineering (CAiSE 2014), Springer LNCS. 8484, pp 332-346.

Sheng., Q., Yu, J., Dustar, S., Eds. (2010) Enabling Context-Aware Web Services: Methods, Architectures, and Technologies. Chapman and Hall/CRC, ISBN 1-43980-985-2

Smanchat, S., Ling, S., Indrawan, M. (2008) A survey on context-aware workflow adaptations, - In The 6th International Conference on Advances in Mobile Computing and Multimedia (MoMM 2008), pp 414-417

Stirna, J., Grabis, J., Henkel, M., \& Zdravkovic, J. (2012) Capability driven development - an approach to support evolving organizations. In The Practice of Enterprise Modeling (PoEM 2012), Springer LNBIP, pp117-131.

Vale, S., Hammoudi, S. (2009) COMODE: A framework for the development of context-aware applications in the context of MDE. In proceedings of the 2009 4th International Conference on Internet and Web Applications and Services (ICIW 2009), pp261-266

Wesenberg, H. (2011) Enterprise Modeling in an Agile World, P. Johannesson, J. Krogstie, A. L. Opdahl (Eds.): In The Practice of Enterprise Modeling (PoEM 2011), Springer LNBIP, pp126130.

Yue, T., Briand, L.C. and Labiche, Y. (2011) A systematic review of transformation approaches between user requirements and analysis models. Requirements Engineering 16, pp 75-99

Zdravkovic, J., Stirna, J., Henkel, M., \& Grabis, J. (2013) Modeling business capabilities and context dependent delivery by cloud services. In proc. of Advanced Information Systems Engineering (CAiSE 2013), Springer LNBIP, pp369-383. 